JALADRI (Vol. 7.1) (2021)
Jurnal Pendidikan Bahasa dan Sastra Daerah
http://jurnal.upmk.ac.id/index.php/jaladri/

\title{
KAJIAN ETNOPEDAGOGIK ADAT PERPANDAYAN DI DESA TARAJU KECAMATAN SINDANGAGUNG KABUPATÉN KUNINGAN SEBAGAI BAHAN PEMBELAJARAN MEMBACA BERBASIS KEARIFAN LOKAL
}

\section{Heti Triwahyuni, Leni Nuraeni, Mimin Suminar}

triwahyuniheti@upmk.ac.id, lenylenz@upmk.ac.id, 165223012@mahasiswa.upmk.ac.id

Program Studi Pendidikan Bahasa dan Sastra Daerah

STKIP Muhammadiyah Kuningan

Gedung A. Lt. 3 Kuningan Jawa Barat

\section{Info Artikel}

Sejarah Artikel:

Diterima 10 Januari 2021

Disetujui 10 April 2021

Dipublikasikan 25 April 2021

Kata Kunci:

Kajian
etnopedagogik,
pembelajaran
membaca,perpanda
yan desa Taraju

\begin{abstract}
Abstrak
Penelitian ini mempunyai latar belakang yang begitu luas, salah satunya yaitu kurangnya pengetahuan masyarakat Desa Taraju tentang kebudayaan Adat rewahan perpandayan. Tujuan dari penelitian ini yaitu : (1) mendeskripsikan kajian etnopegagogik yang ada di adat Rewahan Perpandaian Di Desa Taraju Kecamatan Sindangagung Kabupaten Kuningan (2) mendeskripsikanUnsur Budaya Adat Rewahan Perpandaian Di Desa Taraju Kecamatan Sindangagung Kabupaten Kuningan (3)mendeskripsikan bagaimana Alternatif Pangajaran Maca berbasis Kearifan lokal. Metode yang digunakan dalam penelitian ini adalah Metode kualitatif dengan cara mengorganisasikan data, mendeskripsikan data,menyusun pola, memilih hal yang penting, serta membuat kesimpulan dalam urutan adat rewahan perpandayan di desa Taraju Kecamatan Sindangagung Kabupaten Kuningan. Dengan tehnik mengumpulkan data melalui observasi, wawancara dan dokumentasi. Hasil dari penelitian ini yaitu kajian etnopedagogik yang ada pada adat rewahan perpandayan di desa Taraju terdiri dari 4 kajian etnopedagogik diantaranya 4 catur jati diri insan, 6 moral manusia, 5 gapura pancawaluya dan 3 prilaku nyunda Tri-silas. Unsur budaya dalam adat rewahan perpandayan di desa Taraju terdiri dari 7 unsur budaya. Alternatif pembelajaran basa Sunda berupa Artikel.
\end{abstract}


key world:

Ethnopedagogic studies, learning to read, the village of Taraju

\section{Abstrak}

This research has a very broad background, one of which is the lack of knowledge of the people of Taraju Village about Indigenous culture of rejuvenation. The purpose of this study are: (1) describing ethnopegagogic studies in the custom of Reward Ceremony in Taraju Village Sindangagung Subdistrict Kuningan Regency (2) describing the Customary Cultural Elements of the Rewahan Reward in Taraju Village Sindangagung Subdistrict Kuningan Regency (3) describing ho Alternative Pangaca Alternative is based on Kuningan Local culture. The method used in this study is a qualitative method by organizing data, describing data, arranging patterns, choosing important things, and making conclusions in the order of customary rewards in the village of Taraju, Sindangagung District, Kuningan Regency. With the technique of collecting data through observation, interviews and documentation. The results of this study are the ethnopedagogic studies in the traditional rewards of bathing in the village of Taraju consisting of 4 ethnopedagogic studies including 4 human identity chess, 6 human morals, 5 pancawaluya gates and 3 Trisilas delay behavior. Cultural elements in the traditional rewards of culture in the village of Taraju consist of 7 cultural elements. Alternative learning of Sundanese bases in the form of Arti 


\section{PENDAHULUAN}

Adat rewahan merupakan salasatu kebiasaan masarakat yang harus dilakukan sacara turun temurun. Adat yaitu wujud hubungan antara manusia dengan pribadinya, masyarakatnya, alamnya, ogé pangérannya. Hubungan itu untuk meminta keselamatan kesempurnaan hidup melalui kesadaran dirinya sendiri, lingkungan, alam dan semua kehidupan manusia.

Adat Rewahan perpandaian ini rutin dilakukan setiap setahun sakali pada bulan Rewah yang tempatnya di makam nenek moyang. Kegiatan ini tidak semua masyarakat tau kegiatannya, banyak juga masarakat yang tidak datang ikut kegiatan adat Rewahan.. salahsatu cara untuk menyampaikan adat rewahan yang ada di Desa Taraju yaitu dengan melalui pembelajaran disekolah. Pembelajaran ini menyampaikan mengenai kearifan lokal yang ada pada struktur adat Rewahan diantaranya nilai sosial (kamasarakatan) serta interaksi masarakat pada lingkungannya. Salian itu kearifan lokal yang ada pada adat rewahan bisa di ketahui masarakat.

Oleh sebab itu, peneliti mempunyai tujuan menyampaikan pengetahuan ini pada masyarakat yang belum tau adat rewahan. Penelitian ini yang berjudul "Ulikan Etnopedagogi Adat Rewahan Perpandaian Di Desa Taraju Kecamatan Sindangagung Kab. Kuningan pikeun Pangajaran Maca Berbasis Kearifan Lokal" perlu dilakukan.

\section{METODE PENELITIAN}

Penelitian ini menggunakan metode penelitian kuantitatif deskriptif. Adat Rewahan perpandaian ngan di laksanakeun di Désa Taraju Kecamatan Sindangagung Kabupaten Kuningan. Lokasi tempat penelitian yaitu di daérah makam Sunan Manyak di Désa Taraju. Teknik yang dipakai dalam penelitian ini adalah teknik observasi, teknik wawancara dan teknik dokumentasi. Variabel yang dicapai dalam penelitian ini adalah Étnopédagogik adat perpandaian, unsur budaya dalam adat rewahan an alternatif bahan ajar. Melalui kegiatan dan hasil wawancara kepada tokoh yang terlibat dalam adat rewahan.

\section{HASIL DAN PEMBAHASAN}

Salasatu adat yang ada di Désa Taraju yaitu Rewahan Perpandayan, rewahan perpandayan ini punya tujuan minta doa atau bantuan Allah SWT dengan cara berdoa melalui nenek moyang yang sudah meninggal salah satunya Rama Éyang Radén Sunan Manyak yang dimana selama beliau ada di alam dunia aktif di pekerjaan panday besi. Tujuan dalam meminta doa ini tidak adanya maksud menduakan kesempurnaan Allah SWT tapi dengan cara minta doa melalui Rama Éyang Radén Sunan Manyak selaku perantara untuk menyempurnakan doa pada Allah STW. Rama Éyang Radén Sunan Manyak selama masih di alam dunia dianggap masarakat satempat selaku manusia yang mempunyai sikap, tatakrama yang bagus serta beliau rajin ibadah. (wawancara pa Waslani (kepala Désa Taraju) kemis 11 juni 2020).

Waktu berjalannya kagiatan adat rewahan dilakukan pada tanggal 15 rewah pada tiap tahunnya, sabab mendekati bulan puasa yang salasatunya kegiatan adat rewahan ini melatih diri pribadi menyambut bulan puasa yang merupakan bentuk iman kesolehan individu dan koléktif. Pihak yang ikut pada kagiatan rewahan ini yaitu masyarakat desa Taraju dan masyarakat diluar désa selaku pelaksana inti pada kagiatan ini. Pamaréntahan desa Taraju yang mendukung kegiatan ini. (wawancara bapa Kasma (salaku kuncén dina Adat Rewahan) Sabtu 13 juni 2020)

Sebab masyarakat dijaman sekarang jarang ikut kagiatan adat rewahan dan masarakat di jaman sekarang sudah terbawa budaya budaya yang modérn sahingga budaya yang ada di lingkungana tidak diketahui oleh masyarakat, dengan cara mengenalkan atau memberikan pengetahuan kepada masyarakat salasatunya untuk siswa disekolah yang tidak tau adat rewahan.

salahsatu kegiatan pada Adat rewahan yaitu Ngeséh, ngeséh yaitu kegiatan yang mempunyai tujuan untuk mewujudkan raa syukur kepada Allah sebab dirinya mau melakukan acara hajat besar. (wawancara pak Ewo (salaku Panday besi) senin 15 juni 2020).

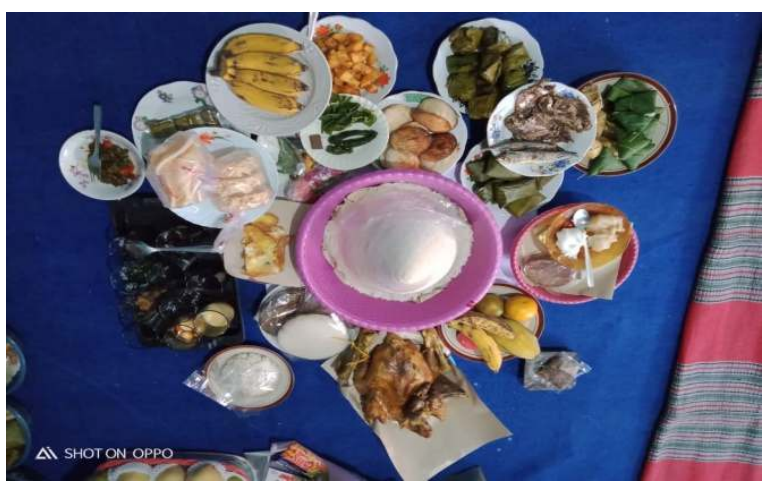


(Foto Pasrén kadaharan ngeséh)

\section{PEMBAHASAN}

1. Kajian Étnopédagogik yang ada pada adat rewahan perpandayan

A. Catur Diri insan

1) Pengkuh agamana

Pada acara rewahan ini masyarakat melaksanakan yasinan dan pengajian

2) Luhur elmuna

Memberikan pengetahuan untuk yang tidak tahu adat rewahan ke para siswa/pelajar yang tentunya jadi penurus kedepannya dalam menjaga adat rewahan ini.

3) Jembar Budayana

Memberikan wawasan luas kepada masyarakat mengenai rasa kemanusiaan masyarakat satu dengan yang lainnya.

4) Rancage gawena

Pada adat rewahan yang termasuk rancagé gawena yaitu masyarakat yang masing masing membantu pekerjaan dalam acara.

B. Moral Kemanusiaan

1) Moral Manusia Terhadap Tuhan Yaitu yasinan dan pengajian bersama

2) Moral Manusia Terhadap Pribadi Yaitu mengikuti kegiatan rewahan dan menyumbangkan makanan atau tenaganya untuk acara tersebut

3) Moral manusia terhadap manusia lain

Yaitu gotong royong antar masyarakat untuk mensukseskan acara rewahan.

5) Moral Manusia Terhadap Alam Yaitu menjaga dan merawat serta melindungi alam sekitar pada kegiatan rewahan.

6) Moral Manusia Terhadap Waktu Yaitu saling mengingatkan sesama masyarakat untuk mengikuti kegiatan ini karna pada dasarnya kegiatan ini ada pada lingkungan sekitar kita.
7) Moral Manusia dalam Mengejar Kepuasan Lahiriah dan Batiniah Yaitu dalam pekerjaan panday besi

C. Gapura Pancawaluya Cangeur,Bageur,Bener,Pinter,Si nger yaitu dalam kegiatan rewahan cageur hate jeung bisa saling bantu sesama ,bener dalam melakukan hal baik

D. Perilaku nyunda Tri-Silas

1) Silih Asih

Yaitu bekerja bersama-sama atau gotong royong

2) Silih Asah

Yaitu ketika kita mendapatkan ilmu pengetahuan atau yang lainnya kita bisa memberikannya kepada yang belum tau, saling mengingatkan.

3) Silih Asuh

Yaitu masarakat saling merangkul masarakat lain tidak memilah milih.

\section{Unsur Budaya pada Adat Rewahan} Perpandayan

A. Bahasa

Dalam basa adat rewahan perpandayan yang dipakai adalah bahasa Sunda.

B. Sistem pengetahuan

Banyak ilmu pengetahuan dalam adat rewahan jadi kegiatan ini perlu di berikan kepada masyarakat yang belum tau akan hal ini utamanya kepada siswa yang akan menjadi generasi penerus.

C. Sistem kemasyarakatan

Pada sistem kemasyarakatan adat rewahan susuan panitianya yaitu:

$\begin{array}{ll}\text { Pelindung } & \text { : PaMaska } \\ \text { Ketua umum } & \text { : PaMaskim } \\ \text { Bendahara } & \text { : Pa Kasma } \\ \text { Sekertaris } & \text { : Pa Suarda }\end{array}$

D. Sistem Peralatan Hidup jeung teknologi

PEkakas Tani diantaranya cangkul, Arit, Koréd dll yang dipakai pada acara rewahan.

E. Sistem Mata Pencaharian Hidup Pada sistem mata pencaharian hidup yaitu selaku panday besi.

F. Sistem Religi 
Pada sistem religi yaitu meminta keselamatan kepada allah SWT.

\section{Alternatif Pangajaran Maca berbasis}

\section{Kearifan lokal}

\section{Adat Rewahan Perpandayan Di Désa \\ Taraju Kecamatan Sindangagung \\ Kabupatén Kuningan \\ $\mathrm{Ku}$ Mimin Suminar}

Dijaman baheula kacaritakeun aya saurang patapa dilingkungan masarakat Désa Taraju nyaéta Buyut Jamini, kadieukeun ngaran Buyut Jamini diganti ku ngaran Radén Éyang Sunan Manyak sabab ngaran éta teu sajalan jeung sajarah anu ayeuna, kukituna ngaranna dipopulerkeun jeung ngaran anu sabenerna nyaéta Radén Éyang Sunan Manyak, anjeuna jalma kahiji di Désa Taraju nu miboga pakasaban dina pandai besi, tuluy ngabogaan putra angkat nyaéta Bapak Béwu (Jaya Wiguna) nalika anjeuna masih dialam dunya aktif dina pakasaban pandai besi di Désa Taraju. Radén Éyang Sunan Manyak wafat tanggal 15 Rewah, hususna di Désa Taraju sok diayakeun acara adat rewahan dina tanggal 15 rewah. Dina ieu acara anu ngabogaan kawajiban anu hususna masarakat Désa Taraju nyaéta para pandai besi.

Ti taun 1965 kadieukeun hususna nu boga pakasaban pandai besi nalika rék ngayakeun kagiatan rewahan kudu ririungan heula. Kagiatan dina acara rewahan ngawengku:1) bebesik makam 2) Yasinan 3) Prosési meuncit domba 4) Dahar babarengan. Diayakeuna adat rewahan ieu lian ti mieling wafatna Radén Éyang téh nyaéta salasahiji cara pikeun generasi ayeuna jeung saterusna bakal kalaksana sabab diajaman ayeuna loba nu teu wawuh kana adat rewahan. Adat rewahan miboga pamaksadan keur ménta tawasul $\mathrm{ka}$ Allah SWT $\mathrm{ku}$ cara ngadoa ngaliwatan karuhun anu geus wafat salasahijina Radén Éyang Sunan Manyak anu dimana salila anjeuna aya dialam dunya aktif dina pakasaban pandai besi, anjeuna salila dialam dunya dianggap $\mathrm{ku}$ masarakat satempat salaku manusa anu miboga sikep jeung tatakrama anu hadé jeung ogé rajin kana ibadah. Dina ménta pidoa ieu henteu aya pamaksadan ngaduakeun Allah SWT tapi ku cara ménta pidoa ngaliwatan ka Radén Éyang Sunan Manyak Tujuan lain tina adat rewahan nyaéta hiji kagiatan anu ngaraketkeun tali duduluran unggal masarakat anu karumpul dina ieu acara rewahan. Dina ngalaksanakeun kagiatan ieu nyaéta panginget yen kagiatan ieuteh ayana di Désa Taraju anu tempatna dilingkungan pasaréan Rama Éyang Sunan Manyak. Salasahiji kagiatan dina Adat rewahan nyaeta Ngeséh, ngeséh nyaéta kagiatan nu miboga pamaksadan pikeun ngawujudkeun rasa syukur ka Gusti Allah lantaran dirina rek ngayakeun hajat gede.

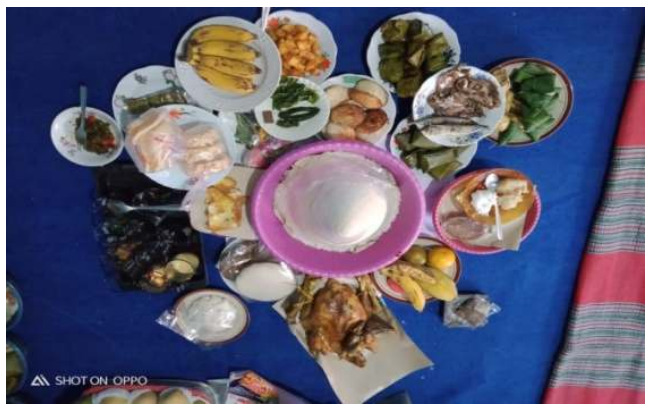

\section{KESIMPULAN}

1. Kajian Étnopédagogik yang ada pada adat rewahan perpandayan yaitu Catur Jati Diri Insan,pada catur diri insan kajian Étnopédagogik ada 4. Moral kamanusiaan, pada Moral Kemanusiaan kajian Étnopédagogik ada 6 .Gapura Pancawaluya, Gapura Pancawaluya mengandung arti Gerbang Kasempurnaan diantaranya ada 5 . Perilaku Nyunda Tri-silas, Prilaku nyunda Tri-silas yang mengandung arti interaksi dilingkungan masarakat dengan cara kebersamaan dan mewujudkan karakter yang baik ada 3 .

2. Unsur Budaya yang ada pada adat rewahan perpandayan ada 6 saperti, Bahasa,sistem pengetahuan, sistem kemasyarakatan,sistem peralatan hidup jeung teknologi, sistem mata pencaharian hidup dan sistem religi. 
3. Alternatif Bahan Ajar Berbasis Kearifan Lokal pembelajaran disekolah selama ini kurang memperhatikan kearifan lokal yang ada di daérahnya sampai generasi muda meninggalkan nilai nila luhur daérahnya. Disisi lain generasi muda di berikan kemampuan menggali poténsi lokal tentu bakal mendapatkan wawasan dan pengetahuan pangawéruh mengenai kearifan lokal adat rewahan perpandaian. Alternatif bahan ajar yang digunakan yaitu berupa Artikel Adat Rewahan perpandayan di Désa Taraju Kecamatan Sindangagung Kabupaten Kuningan.

\section{REFERENSI}

Al-baiti,2015. Kajian Kearifan Lokal Kelompok Budaya dari lembah baliem Wamena Papua.

Alwasilah, A.Ch dkk, (2009). Etnopedagpgi (Landasan Praktek Pendidikan Dan Pendidikan Guru). Kiblat. Bandung.

Aminuddin. 1990. Pengembangan Penelitian Kualitatif dalam Bidang Bahasa dan Sastra. Malang: Yayasan Asah Asih Aspuh.

Arikunto, S. 2013. Prosedur Penelitian Suatu Pendekatan Praktik. Jakarta: PT Rineka Cipta.

B.Rahmanto. 20015. Metode Pengajaran Sastra. Yogyakarta: Kanisius

Danadibrata, R.A. 2019. Kamus Basa Sunda. Bandung: PT. Kiblat Buku Utama.

Koentjaraingrat. (1992). Kebudayaan Mentalitas dan Pembangunan. Jakarta: PT. Gramedia Pustaka Umum.

Ruhimat, Toto. 2013. Kurikulum dan pembelajaran. Bandung: PT. Raja Grafindo Pusaka

Sudaryat, Y. (2015). Wawasan Kesundaan. Jurusan Pendidikan Bahasa Daerah UPI Bandung. Bandung.

Sugiyono. (2014). Metode Penelitian Penelitian Pendidikan Pendekatan Kuantitatif, Kualitatif,dan R\&D. Bandung: Alfabeta.

Sutopo. 2006. Metodologi Penelitian Kualitatif. Surakarta: UNS.
Waryandani, Wuri. 2011. Pembelajaran Berbasis Multikultural di Sekolah Dasar untuk Mengembangkan Karakter Bangsa. Yogyakarta: UNY. 